\title{
A construção do plano local como atribuição das equipes de Saúde da Família: a experiência de três áreas programáticas do Município do Rio de Janeiro
}

| ${ }^{1}$ Patricia Campos Elia, ${ }^{2}$ Marilene Cabral do Nascimento |

Resumo: As atribuições das equipes de Saúde da Família incluem a elaboração de um plano local, com participação da comunidade, considerando as peculiaridades e necessidades de saúde em cada território. Através de um estudo de caso com abordagem qualitativa, analisou-se o processo de planejamento local em três equipes, situadas em diferentes áreas programáticas do município do Rio de Janeiro. A seleção priorizou maior tempo de implantação e de estabilidade na composição das equipes, considerando a probabilidade de maior integração interna e junto a seus territórios. Participaram todos os profissionais das equipes e seus supervisores regionais. Os dados foram coletados através de observação direta das reuniōes das equipes e entrevistas semiestruturadas. Optou-se pela análise de conteúdo com abordagem temática, utilizando as categorias teóricas de risco, vulnerabilidade e planejamento participativo. Os resultados mostraram um processo de planejamento local ainda incipiente, sem definição clara de metas comuns, subutilização de critérios e instrumentos preconizados, tendência normativa e focado em aspectos biológicos. Entre as sugestôes para fazer avançar o planejamento, destacaram-se adequação do espaço físico nas unidades de saúde, estabilidade no fornecimento de insumos, regulação da rede de serviços, inclusão de um profissional administrativo em cada unidade de saúde e ações de educação permanente. Entende-se que a formulação e implementação de metodologias e instrumentos básicos capazes de traduzir as diretrizes da Estratégia de Saúde da Família e se adequar às peculiaridades de cada território, junto ao fortalecimento de uma cultura de planejamento participativo, se mostram fundamentais para a integração e qualificação do trabalho nessas equipes.

> Palavras-chave: Estratégia de Saúde da Família; Planejamento em Saúde; Comunicação em Saúde; Atenção Primária em Saúde.

\footnotetext{
1 Graduação em Medicina pela Universidade do Estado do Rio de Janeiro (UERJ); Mestrado Profissional em Saúde da Família pela Universidade Estácio de Sá (UNESA); médica de família e comunidade e pediatra na Secretaria Municipal de Saúde e Defesa Civil do Rio de Janeiro. Endereço eletrônico: eliap19@ yahoo.com.br

2 Doutorado em Saúde Coletiva pelo IMS-UERJ; professora adjunta no Instituto de Saúde da Comunidade da Universidade Federal Fluminense. Endereço eletrônico: mnascimento3@ gmail.com
}

Recebido em: 27/05/2010 Aprovado em: 16/10/2010 


\section{Introdução}

Este artigo apresenta resultados de pesquisa sobre o processo de planejamento local em equipes de Saúde da Família, em três áreas administrativas do município do Rio de Janeiro.

O Programa de Saúde da Família (PSF) surgiu em 1994 e em 1997 foi redefinido como Estratégia de Saúde da Família (ESF), com a proposta de se constituir como eixo estruturante do Sistema Único de Saúde (SUS), porta de entrada e local privilegiado para a prestação de ações e serviços de saúde, visando a reordenar o modelo de atenção (BRASIL, 2003). Dados de 2009 do Ministério da Saúde informaram a existência de 30.328 equipes de Saúde da Família implantadas, com uma cobertura superior a $50 \%$ da população brasileira. O município do Rio de Janeiro contava, no mesmo ano, com 165 equipes e cobertura de 9,24\% da população (BRASIL, 2010).

AoperacionalidadedaESFsedáatravés dotrabalhodeequipesmultiprofissionais, dirigido às populações em territórios delimitados com aproximadamente mil famílias ou quatro mil habitantes, pelas quais assumem responsabilidade. Segundo Milton Santos (1994), o território expressa características culturais, socioeconômicas, ambientais - o modo de vida da população que nele vive. Desta perspectiva, o território de abrangência das equipes é entendido como 'território vivo', levando-se em conta, além de sua natureza espacial, a ação humana (Silveira; Santos, 2001 apud PAIM, 2003). Espera-se que em cada território as equipes busquem estabelecer relaçóes existentes entre o adoecer e a vida cotidiana e, a partir disto, identificar problemas, prioridades e mobilizar recursos potenciais para atender às necessidades de saúde da comunidade (CAMPOS, 2003).

Cada equipe é composta minimamente por um médico generalista, um enfermeiro, um auxiliar de enfermagem e seis agentes comunitários de saúde, e pode ser ampliada, passando a contar também com um dentista, um auxiliar de consultório dentário e/ou um técnico em higiene dental. A atuação das equipes ocorre sobretudo em unidades básicas de saúde e nas residências e espaços da comunidade, com a proposta de se constituir como porta de entrada de um sistema hierarquizado e regionalizado de saúde.

Entre as atribuições das equipes de Saúde da Família está a de "elaborar, com a participação da comunidade, um plano local para enfrentamento dos principais determinantes de saúde/doença; inclusive com ações intersetoriais”. 
A construção deste plano local envolve a elaboração de um diagnóstico local, com a identificação dos problemas de saúde e situações de risco e vulnerabilidade aos quais a população está exposta - entendendo-se risco como a probabilidade de que um evento desfavorável venha a ocorrer, e vulnerabilidade como a razão entre esta probabilidade e a capacidade para seu enfrentamento (SÁNCHES; BERTOLOZZI, 2007). O plano local envolve também a definição de critérios para a eleição de prioridades, a pactuação de metas, a definição de propostas de ação e de seus responsáveis, o monitoramento e a avaliação de resultados (BRASIL/MS, 2006; ANDRADE, 2001).

Esta proposta de planejamento prevê o reconhecimento das possibilidades dos atores sociais para superar dificuldades e o estabelecimento e pactuação política de compromissos, em uma relação de diálogo. Isso coloca em destaque a eleição de estratégias de comunicação adequadas, capazes de favorecer a expressão, o diálogo e a pactuação entre diferentes vozes e interesses: profissionais das equipes, usuários dos serviços, lideranças comunitárias, gestores e representantes de instituiçôes (CARDOSO, 2005; ARAUJO; CARDOSO, 2007).

A metodologia de planejamento com enfoque participativo agrega a problematização para a identificação de necessidades e recursos disponíveis em um determinado espaço, com a contribuição de atores sociais que vivenciam diretamente os problemas identificados. Esta metodologia se contrapõe à perspectiva normativa de planejamento, na qual predomina a hierarquia funcional na relação entre os diferentes atores, em que uns planejam e outros executam (RIVERA, 1989; TAKEDA, 2004; EULÁLIO, 2007).

Historicamente, a proposta de planejamento se desenvolveu com as necessidades da sociedade industrial, com um caráter predominantemente normativo, ou seja, que destaca a figura do planejador, associado a uma função normativa e de mando. Na década de 1980, Carlos Matus, economista chileno, sistematizou um método conhecido como Planejamento Estratégico Situacional (PES), que se diferenciou do planejamento normativo, entre outras coisas, por não valorizar a figura tradicional do planejador. Na concepção do PES, o planejamento é efetuado por um grupo de atores, com um caráter interativo (ARTMANN, 1993). Ao ser encaminhado de maneira participativa, o planejamento permite explicitar democraticamente os objetivos e compartilhar compromissos, de forma a fortalecer a interação. 
$\mathrm{Na}$ ESF, a proposta de planejamento local prevê a participação social e a integração intra e intersetorial, considera os determinantes e condicionantes de saúde e contempla as peculiaridades de saúde locorregionais. A elaboração do plano local é, desta perspectiva, uma tarefa complexa que demanda instrumentos de epidemiologia, metodologias e técnicas de planejamento e de comunicação, entre outras.

Considerando estes aspectos, o estudo analisa o processo de planejamento local das equipes de Saúde da Família para a realização do diagnóstico, eleição de prioridades, pactuação de metas, definição de propostas de ação e avaliação de resultados, visando o enfrentamento dos problemas identificados nos territórios.

\section{Procedimentos metodológicos}

A pesquisa utilizou metodologia qualitativa, através de um estudo de caso de tipo exploratório e descritivo. Embora o planejamento seja tema frequente em estudos de Saúde Coletiva e da ESF, observamos que sua abordagem no nível dos territórios adscritos a equipes de Saúde da Família é ainda pouco explorada na literatura.

O cenário da pesquisa incluiu três equipes de Saúde da Família, distribuídas em três módulos de Saúde da Família, cada um deles localizado em uma área programática (AP) do município do Rio de Janeiro. O critério de eleição foi o maior tempo de implantação e de estabilidade das equipes, considerando-se a probabilidade de seus integrantes terem acumulado maior integração interna e com as comunidades.

Foram convidados a participar na pesquisa profissionais das equipes selecionadas e seus respectivos supervisores, que atuavam nos grupos de apoio técnico (GAT) ${ }^{1}$, o que conformou um total de 27 participantes: três médicos, três enfermeiros, três técnicos de enfermagem, um odontólogo, dois auxiliares de consultório dentário (ACD), 12 agentes comunitários de saúde (ACS) e três profissionais dos GATs. Após os esclarecimentos sobre os objetivos e procedimentos da pesquisa, os participantes foram convidados a assinar o termo de consentimento livre e esclarecido.

$\mathrm{Na}$ coleta de dados, utilizamos a observação direta de reuniōes das equipes, por entendermos que estas são um espaço privilegiado para as atividades de planejamento de ações. Foram observadas quatro reuniōes consecutivas de cada 
equipe, entre junho e outubro de 2008, o que totalizou 12 reuniões. Através

de entrevistas individuais semiestruturadas, complementamos os dados sobre o processo de trabalho das equipes em relação às atividades de planejamento. Quinze profissionais aceitaram participar nas entrevistas - três médicos, três enfermeiros, um odontólogo, um técnico de enfermagem, cinco ACS e dois supervisores do GAT. Antes da realização das entrevistas, foi realizado um testepiloto junto a uma equipe que atua fora do cenário pesquisado, com a finalidade de adequar o roteiro semiestruturado.

Os dados da observação foram registrados em diário de campo e as entrevistas, gravadas e posteriormente transcritas. Os profissionais foram identificados por um código constituído por número e letras correspondentes a sua categoria profissional. $\mathrm{O}$ conjunto de dados coletado foi submetido à análise de conteúdo com abordagem temática (BARDIN, 2007), destacando-se núcleos de sentidos e categorias empíricas que se consolidaram nos seguintes temas: o processo de elaboração do plano local; as vozes do planejamento local; principais dificuldades e sugestôes relacionadas ao planejamento plano local. As categorias analíticas utilizadas foram risco, vulnerabilidade e planejamento participativo.

O projeto de pesquisa foi aprovado pelo Comitê de Ética em Pesquisa da Secretaria Municipal de Saúde do Rio de Janeiro, através do parecer no 0079.0.314.000-08, de 19 de maio de 2008.

\section{O processo de elaboração do plano local}

As equipes observadas realizavam reuniōes semanais, com duração média de três horas e registros em livro de ata. Apenas uma equipe contava com espaço específico para reuniōes, as outras duas utilizavam a sala do médico para esta finalidade. Também em apenas uma equipe se observou a prática de definição prévia da pauta a ser debatida, a partir de pendências de reuniões anteriores e sugestôes dos participantes.

Os temas discutidos nas reuniōes observadas foram bem diversos, conforme se pode observar a seguir. Todos os temas tratados revelaram relação com a proposta de planejamento, em menor ou maior grau.

- Espaço físico: limpeza do módulo, obras de manutenção e adequação do espaço; divisão do espaço entre os diferentes profissionais.

- Insumos: falta, estoque e aquisição (balança, luvas, seringas, medicamentos etc.). 
- Recursos humanos: faltas, férias, seleção, equipes incompletas, educação permanente.

- Rede: referência e contrarreferência, articulações intra e intersetoriais.

- Assistência: agendamento e realização de consultas e exames, visitas domiciliares, grupos de usuários, discussão de casos.

As entrevistas indicaram que, além das reuniōes semanais, existe a prática de reuniōes anuais destinadas especificamente ao planejamento local, geralmente no final ou início de cada ano: "Nós fazemos uma reunião no fim do ano para um balanço e elaboração do plano de ação para o ano seguinte (TE2). Entretanto, durante o período da pesquisa, não houve a realização desta modalidade de reunião.

\section{Diagnóstico}

O diagnóstico local é a etapa inicial do processo de planejamento local; executada adequadamente permite à equipe identificar os fatores determinantes e condicionantes do processo saúde-doença no território, os principais riscos de adoecimento e os grupos mais expostos a eles, além do impacto de suas ações sobre o nível de saúde da população.

As informações presentes no Sistema de Informação da Atenção Básica (SIAB) são fundamentais para este diagnóstico, particularmente os dados de cadastramento e acompanhamento das famílias, constantes nas fichas A e B, respectivamente. De acordo com o Ministério da Saúde (BRASIL, 2003b), o SIAB é um sistema idealizado para agregar e processar as informações sobre a população visitada. É alimentado e atualizado com dados coletados nas visitas domiciliares (VD), trazidos pelos agentes comunitários ou outros profissionais da equipe, e os decorrentes da demanda espontânea. Alguns entrevistados confirmaram a importância deste instrumento no planejamento de açôes.

O diagnostico é dinâmico, a equipe o faz pela VD [visitas domiciliares], pela demanda que chega à unidade, mas o cadastramento [do SIAB] é uma ferramenta imprescindível. A equipe tem que observar os dados da ficha $\mathrm{A}$ e as informações que o agente traz todo o mês. (M3)

O SIAB permite também gerar relatórios mensais sobre a situação de saúde e produzir ações e serviços nas equipes. Esses relatórios informam, por exemplo, o número de crianças com baixo-peso ao nascer ou desnutridas, de internações e 
óbitos ocorridos no território, de visitas domiciliares realizadas ou de consultas de pré-natal, permitindo desta forma que se trace um panorama de saúde local e se avalie a qualidade dos serviços prestados (AZEVEDO et al., 2006). Entretanto, a despeito da importância atribuída ao SIAB para o diagnóstico local, observouse baixa utilização dos seus dados pelos profissionais das equipes estudadas. Em nenhuma das doze reuniōes observadas no estudo os dados e relatórios do SIAB foram discutidos e poucos profissionais declararam, nas entrevistas, sua utilização.

Outro instrumento subutilizado nas reunióes observadas foi o mapa da área de abrangência das equipes. Estes mapas são elaborados com base em dados obtidos em VD e no SIAB. Neles são assinalados os recursos existentes na comunidade, os principais riscos e potencialidades locais identificados. Permitem uma visualização espacial das informaçóes, destacando a presença de riscos e das famílias em risco. Todas as equipes observadas possuíam um mapa de seu território, mas as formas de confecção e as informações registradas eram variadas. Entretanto, a exemplo do que se observou com o SIAB, os mapas também foram pouco valorizados no processo de diagnóstico e planejamento das ações pelas equipes.

A subutilização destes instrumentos, apesar de estarem disponíveis às equipes, contribuiu para a predominância de uma abordagem biologicista no diagnóstico discutido pelos profissionais em suas reuniōes semanais, considerando pouco o conceito ampliado de saúde, os fatores determinantes e condicionantes de saúde-doença e os critérios de risco e vulnerabilidade. Aspectos do território, contemplados no SIAB, como os ambientais e socioeconômicos, foram pouco mencionados nas reuniōes.

Acredito que colher dados sobre hipertensão arterial, diabetes, acamados, hanseníase é fazer o diagnóstico. (ACS2)

Levantamento epidemiológico com olhar para o território? [silêncio] Só mesmo o diagnóstico da área feito lá no inicio e não sei se foi usado para planejar açôes. (O1)

O diagnóstico tem uma parte macro, do território; este está sem responsáveis. Observo que o processo de trabalho das equipes está cristalizado. Fizemos uma oficina de processo de trabalho, melhorou, estão caminhando. (SO1)

Realizado de maneira pouco abrangente e reflexiva, o diagnóstico limita a percepção do nível de saúde da população e de suas necessidades, como também a avaliação das ações desenvolvidas pelas equipes. Isso, por sua vez, apresenta reflexos nas etapas subsequentes do planejamento, como a definição de prioridades de açôes. 


\section{Critérios e instrumentos utilizados para a eleição de prioridade de ações}

A definição de prioridades de ações também se concentrou em aspectos biológicos, sem considerar suficientemente aspectos socioambientais na identificação de riscos e vulnerabilidades, como ilustra a seguinte fala:

O objetivo da equipe é acompanhar diabéticos, hipertensos, gestantes, explicar sobre os medicamentos; nas reuniões de equipe a gente traça uma estratégia para melhorar a vida destas pessoas. (ACS2)

Em uma das equipes pesquisadas, um profissional mencionou a utilização de uma adaptação da Escala de Risco de Coelho, por iniciativa de estudantes residentes que atuavam na equipe. Trata-se de uma técnica que propõe a pontuação de risco familiar com base em informaçooes da ficha A do SIAB, e permite à equipe incorporar o conceito ampliado de saúde e os critérios de risco e vulnerabilidade em suas atividades de planejamento (COELHO; SAVASSI, 2004). O mesmo profissional citou a inscrição no Programa Bolsa Família (programa do Governo Federal que transfere renda direta a famílias em situação de pobreza e pobreza extrema) como instrumento para identificação de famílias em situação de vulnerabilidade e risco. Entretanto, a utilização destes critérios e instrumentos se mostrou pontual e pouco consolidada nas equipes, inclusive no interior da equipe na qual atuava o profissional referido.

\section{Pactuação de metas}

A pactuação de metas nas equipes, por sua vez, se revelou fortemente apoiada nos indicadores de saúde para a atenção básica definidos pelo Ministério da Saúde MS (BRASIL, 2006). Embora os profissionais das equipes utilizassem o termo "metas do Ministério", o documento ministerial indica a necessidade de cada município definir, dentro dos indicadores propostos, as metas a serem alcançadas no seu nível de atuação, respeitando as especificidades e possibilidades locais. No Plano Municipal de Saúde do Rio de Janeiro, estes indicadores se consolidaram em uma agenda municipal (RIO DE JANEIRO, 2005). Entretanto, esta agenda municipal possivelmente não fora sido discutida com as equipes pesquisadas: os profissionais revelaram conhecer sua existência, mas desconhecerem as metas propostas no referido documento. 
Isto pode explicar, em parte, a ausência de um painel de situação nas unidades de saúde estudadas. Este painel é uma recomendação do Ministério da Saúde, em sua proposta de Avaliação para a Melhora da Qualidade da Estratégia de Saúde da Família - AMQ (BRASIL, 2006). O painel - ou placar - possibilita a visualização de informações obtidas através do SIAB sobre os principais resultados da equipe, em confronto com as metas pactuadas pelos próprios profissionais. Seu objetivo é facilitar o acompanhamento do impacto das ações desenvolvidas pela equipe.

Ao lado disto, cada profissional mostrou entender de forma distinta as necessidades de saúde e prioridades de ação, quase sempre em associação a suas próprias atribuições e procedimentos. Observou-se a ausência de um discurso mais homogêneo na percepção de metas da equipe, o que pode estar sinalizando que estas metas não estejam sendo clara e suficientemente estabelecidas pelos profissionais. Embora cada categoria profissional possa apresentar particularidades em relação às metas da equipe, é importante que esta possa formular e compartilhar metas comuns, reconhecidas pelo conjunto de seus membros.

Como consequência, havia uma dificuldade dos profissionais em relacionar claramente os resultados esperados de seu trabalho ao cumprimento de metas pactuadas, como, por exemplo, a melhoria de condições específicas no território. Entendemos que a limitação da percepção sobre a finalidade das ações desenvolvidas tende a favorecer uma prática burocratizada e alienada.

O cenário estudado apontou, de uma maneira geral, uma dinâmica ainda incipiente na discussão de prioridades e metas a partir de fatores de risco, vulnerabilidades e necessidades de saúde do território local e seus condicionantes e determinantes sociais. Os indicadores definidos pelo MS e pelo GAT se mostraram as principais referências consideradas no planejamento de ações, de uma perspectiva predominantemente biológica. Não observamos a menção clara a metas pactuadas e compartilhadas pelo conjunto dos profissionais, pautadas no território local de abrangência das equipes, considerando suas peculiaridades, necessidades e realidades.

As metas a equipe não se prende muito, é mais o GAT, o GAT vem nas reuniões uma vez por semana, querem acompanhamentos e para atingir $100 \%$ nem sempre depende da gente. (M2)

Esta situação corrobora a avaliação de Turci (2009), segundo a qual o pacto de indicadores, a despeito de sua potencialidade, continua sendo tratado em alguns 
estados e municípios de forma burocrática, fragmentada e pontual, com uma abordagem normativa, não tendo sido incorporado adequadamente na rotina dos serviços de saúde. Esta forma de encaminhamento revela um traço ainda centralizador no planejamento que tende a limitar a autonomia da equipe e suas possibilidades de pactuação de metas adequadas ao seu território de abrangência.

\section{Propostas de ação}

As propostas de ação mais mencionadas foram os grupos de usuários, as visitas domiciliares, além do agendamento de consultas médicas e exames. Ações intersetoriais, embora presentes foram pouco relatadas. Os grupos nomeados foram os de puericultura, adolescentes, planejamento familiar, gestantes, idosos, portadores de diabetes mellitus e hipertensão arterial, anti-tabagismo e artesanato com foco em pessoas com transtornos mentais. Como se pode perceber, a organização dos grupos considera grupos etários, doenças e agravos prevalentes, e atividades preventivas. A metodologia informacional, com foco na doença, foi a mais citada ao se relatar a organização desses grupos.

Quando participo do grupo de pediatria, faço um relatório para o médico, o grupo reúne todos que precisam de informação e o médico passa. (ACS1)

[...] enquanto faço a palestra para os pais, vocês [ACS] têm que ficar com as crianças. (M1)

Apesar da predominância da proposta de transmissão de informações com enfoque biológico, houve relatos de grupos com abordagem lúdica e voltados à promoção da saúde, como ilustra a realização de uma atividade (dança sênior) com o objetivo de promover a integração social de idosos e estimular a cognição e os aparelhos locomotor e circulatório.

Identificamos que a população idosa estava muito fechada dentro de casa, inclusive comprometimento da saúde mental. [...] Hoje fazem dança sênior com a enfermeira [...] Trabalhamos muito com a promoção de saúde. Quando a situação está complicada, encaminhamos. (TE2)

As visitas domiciliares (VD) também mereceram destaque dos profissionais, ao mencionarem a programação de ações na equipe. Entretanto, muitos profissionais declararam ter dificuldade em manter a frequência de VD programada, devido à sobrecarga de atividades na equipe. Entre as açôes intersetoriais mencionadas, os profissionais destacaram uma parceria com a Companhia Municipal de Limpeza Urbana (Comlurb). 
Os grupos de usuários e as VD são estratégias de organização da oferta, de acordo com a avaliação que as equipes fazem das necessidades de saúde da população. Com isto, é possível reduzir a demanda espontânea e oferecer uma atenção mais integral às famílias, que considere, além das ações curativas e de controle, a prevenção de doenças e agravos e a promoção da saúde. O enfoque da promoção, entretanto, se mostrou pouco contemplado na programação de ações nas equipes estudadas, como ilustram as falas seguintes:

Observo que as equipes têm um trabalho organizado, porém ainda cunhado no biológico. A promoção fica um pouco mais de lado em função das atividades assistenciais, há uma demanda para isso. (SO2)

Observamos que no ano passado, a captação de preventivos estava baixa [...] e o cuidado com os hipertensos estava meio solto. Então decidimos priorizar certas açôes. (E3)

Vocês podem separar então quem merece uma VD: pacientes em abandono de tratamento, pacientes que não tomam remédios. (E1)

De uma maneira geral, é possível afirmar que a programação de ações mostrou frágil associação com metas definidas pela equipe. Ficou visível a dificuldade dos profissionais em ampliar suas ações para além de fatores biológicos, como também de utilizar práticas comunicativas dialógicas e participativas nos grupos de usuários.

\section{Monitoramento e avaliação}

Ações de monitoramento e avaliação permitem verificar se as metas estão sendo cumpridas, os resultados alcançados, se o processo de trabalho está adequado e o planejamento necessita ou não de ajustes. Segundo Donabedian (apud REIS et al., 1990), a avaliação do cuidado em saúde deve ter um caráter permanente, podendo se dar em três componentes - estrutura, processo e resultado - com possibilidades de combinaçóes entre eles. Ela é parte do processo de planejamento e deve contribuir para o aperfeiçoamento gradual e constante das ações e serviços, devendo ser considerada a perspectiva de gestores, profissionais e usuários.

Os profissionais relataram que a avaliação de ações acontece prioritariamente em encontros anuais.

A gente tenta alcançar as metas, mas nem sempre a gente consegue. Geralmente no início do ano a gente discute na equipe o que a gente pode fazer para melhorar, o que a gente deixou de fazer no ano anterior. (E3)

Nós fazemos uma reunião no fim do ano para um balanço e elaboração do plano de ação para o ano seguinte. Estamos sempre abertos às propostas do GAT. Para mim, o 
A exemplo das demais etapas que compóem o planejamento local, o monitoramento e a avaliação das ações e serviços também se mostraram presentes, mas de maneira incipiente e descontínua.

\section{As vozes do planejamento local}

Pudemos observar diferenças entre as vozes participantes nas reuniōes observadas. Percebemos que foi constante nas três equipes a liderança de um profissional na condução dos trabalhos, através de uma participação mais ativa comparada a dos demais, seja na coordenação das reuniões, na indicação de sugestões para a pauta, na proposição de encaminhamentos ou ainda na divisão de tarefas dentro da equipe. Em uma delas, a liderança foi nitidamente exercida pelo médico; em outras duas, o enfermeiro e o técnico de enfermagem ocuparam os lugares mais centrais de fala. $\mathrm{O}$ médico, sendo ou não o líder na equipe, se mostrou frequentemente um interlocutor de destaque no grupo.

A participação dos agentes comunitários de saúde (ACS), entretanto, se revelou reduzida em comparação a dos demais profissionais. Foi frequente observá-los em conversa paralela entre si, demonstrando baixa atenção aos temas tratados. A participação destes profissionais acontecia principalmente quando solicitados a fornecer informaçōes ou a fazer os agendamentos de consultas e exames. Através de uma escala, a enfermeira distribuía tarefas aos ACS, como a realização de VD ou a participação em atividades de grupo.

Temos uma agenda mensal com nossas atividades, os turnos nos grupos, as visitas domiciliares [...] A enfermeira faz as escalas e coloca no quadro de avisos. Nas VD com o médico e a enfermeira, eles escolhem as prioridades. (ACS3)

Contudo, os ACS afirmaram sua participação no processo de trabalho e na definição de açôes, expressando um sentido de pertença ao grupo e de contribuição em suas deliberações.

O objetivo da equipe é acompanhar diabéticos, hipertensos, explicar sobre os medicamentos. Nas reuniões de equipe a gente traça uma estratégia para melhorar a vida destas pessoas. (ACS3)

As reunióes são importantes. Nelas discutimos os casos, a equipe fica mais junta, vê as prioridades e pode ajudar mais as pessoas [...] Observamos que as DST [doenças sexualmente transmissíveis] têm aumentado, então vamos chamar mais para o preventivo. (ACS4) 
Apenas uma equipe contou com a presença do odontólogo em suas reuniōes, que mostrou uma participação ativa. A fala deste profissional na entrevista confirmou a participação reduzida dos ACS no planejamento de ações:

Nossa meta é o acompanhamento. Temos que acompanhar crianças menores de dois anos, portadores de hipertensão arterial, diabetes mellitus. As metas foram pactuadas pelo GAT e pela equipe técnica [referindo-se aos profissionais com escolaridade em nível superior]

A participação de gestores do nível regional (vinculados ao grupo de apoio técnico - GAT) e central (Secretaria Municipal de Saúde - SMS/RJ) nas reuniões e atividades de planejamento obteve uma dupla avaliação por parte dos profissionais entrevistados. Várias falas destacaram dificuldades no relacionamento com estes gestores, apontando um excesso de cobranças contraposto a um apoio insuficiente às ações das equipes. Outras, entretanto, assinalaram a contribuição dos gestores para o avanço das atividades de planejamento e desenvolvimento das ações de saúde. Contudo, todos ressaltaram a forte presença do GAT na definição e acompanhamento de metas para as equipes.

[...] atingir 100\% [das metas] nem sempre depende da gente [silêncio]. Falta um pouco de confiança do GAT na gente. (M2)

[...] quando o novo GAT entrou mudou tudo, deu um olhar diferente [...] A gente trabalhava sem preocupação de fazer o diagnóstico, hoje nos já temos essa visão [...] hoje a gente tenta trabalhar em cima de um diagnóstico, olhando para o SIAB e com planejamento. (E1)

O GAT foi identificado ora como instância de autoridade que orienta e dá suporte, ora como instância autoritária que impõe e cobra. As entrevistas revelaram que estas diferenças expressam situações específicas, mas também diferentes estratégias de relacionamento de cada grupo de supervisão com suas respectivas equipes. Em equipes incompletas, por exemplo, com maior sobrecarga de atividades, as resistências dos profissionais tendem a se acirrar frente a novas demandas, e nem sempre há um reconhecimento do problema pelos supervisores.

Nas reuniōes em que o GAT teve uma atuação mais normativa e centralizadora, a participação dos demais profissionais se mostrou reduzida, em especial a dos ACS. O silêncio, entretanto, não significa necessariamente concordância ou adesão aos encaminhamentos, mas uma estratégia frente a relações fortemente marcadas por posiçōes hierárquicas. Uma liderança autoritária vai de encontro à proposta de planejamento participativo, que depende da expressão de diferentes atores e 
projetos, do diálogo aberto, da pactuação de compromissos e responsabilidades e do reconhecimento das possibilidades de cada equipe para superar dificuldades.

Entendemos que uma atuação autoritária do gestor, além de promover resistências e conflitos nas equipes, reforça a dependência dos profissionais no desempenho de suas atividades. Uma prática comunicativa e participativa, que considere resistências, conflitos, incertezas e mudanças na busca de consensos, contribui por sua vez na construção de projetos comuns, pertinentes às possibilidades das equipes e às necessidades de saúde em cada território específico.

Os traços de autoritarismo na comunicação não se limitaram à relação entre gestores e equipes, mas estiveram presentes também entre os profissionais das equipes, apoiados em posições hierárquicas e articuladas ao saber científico. A organização das ações e a distribuição de tarefas expressaram uma tendência verticalizada e pouco participativa. $\mathrm{O}$ espaço para o diálogo necessário ao diagnóstico local, à avaliação de riscos e ao planejamento participativo de ações se apresentou limitado.

Foucault (2007, p. 183) chama a atenção para o conceito de rede de poder, em que os indivíduos estão sempre em posição de exercer e sofrer sua ação.

[...] o poder - desde que não seja considerado de muito longe - não é algo que possa ser dividido entre os que o possuem e o detêm exclusivamente e os que não o possuem e a ele são submetidos. [...] O poder funciona em rede. Nas suas malhas os indivíduos estão sempre em posição de exercer e sofrer uma ação.

Neste sentido, ou pelo menos em um dos sentidos possíveis que o conceito contempla, é possível associar a restrição ao diálogo e à pactuação na construção e desenvolvimento das ações a situações de omissão, descompromisso e até mesmo de boicote presentes em algumas equipes (CARDOSO; NASCIMENTO, 2010).

Quantoà participação dacomunidade, os profissionais entrevistados declararam que esta acontece principalmente nos grupos de usuários; o planejamento de ações, entretanto, ainda que considere a demanda da comunidade, é definido essencialmente pela equipe de saúde.

A comunidade tem voz e vem sempre reclamar que tem ratos nos domicílios e lixo na cachoeira, e com isso a equipe planeja ações educativas e mutirôes [...] (TE2)

Nossos parceiros são fundamentais, existem lideranças da comunidade que motivam os moradores e participar dos nossos grupos, por exemplo [...] As metas são estabelecidas pela equipe em reuniōes, nisto a comunidade não participa. (M3) 
A presença dos ACS nas equipes, na condição de moradores da comunidade, e a dinâmica de trabalho destes profissionais em visitas domiciliares e grupos de usuários, possibilitam uma ampliação do espaço de diálogo com a comunidade. Entretanto, a participação da comunidade no planejamento de ações de saúde se mostrou de maneira indireta e também fragmentada e descontínua.

Uma equipe mencionou a organização de um conselho gestor local, instância deliberativa composta de representantes de profissionais e usuários dos serviços, com a intenção de garantir uma participação mais ativa da comunidade na elaboração do plano local. Porém, esta participação não foi mencionada nas reuniōes da equipe durante o período de observação da pesquisa.

\section{Principais dificuldades e sugestões relacionadas ao planejamento local}

Os profissionais entrevistados citaram diversos fatores que dificultam ou facilitam o processo de planejamento de ações. No primeiro grupo, destacaram a inadequação e a manutenção insuficiente do espaço físico; irregularidades no fornecimento de materiais e medicamentos; dificuldades no preenchimento e utilização do sistema de informações on line decorrentes de equipamentos obsoletos e conexões lentas; equipes incompletas e insuficientemente motivadas, além de problemas na referência e contrarreferência de pacientes. De acordo com os entrevistados, estas limitações impactam não apenas as atividades de planejamento, mas todo o processo de trabalho das equipes, gerando sobrecarga de atividades.

O que dificulta? A falta de tempo, o excesso de cobrança, a equipe incompleta... A gente sempre trabalhou sufocado pela demanda livre [...]. Este ano, a dengue prejudicou muito. (M1)

O que dificulta é a sobrecarga de tarefas... Falta organizar o meu horário [...] faz falta um profissional administrativo [...] A rede cai toda hora, não conseguimos digitar e salvar as informações, é muito lento [...] O município do Rio tem que melhorar [...] a referência e contratreferência, caso contrário não podemos planejar nada. (M2)

As dificuldades logísticas, como falta de material, prejudicam a resolutividade da equipe, e tudo isso diminui nossa credibilidade junto à comunidade. (E2)

O grande número de famílias em cada microárea, tem ACS com 179 famílias [...] Além disso, é muito importante ter os ACS capacitados e com gás. Além disso, é muito bom fazer cursos. (E1) 
Os problemas relatados podem estar contribuindo para a subutilização de instrumentos de planejamento disponíveis na equipe e preconizados pelo Ministério da Saúde, como o SIAB e o mapa da área de abrangência. Ao lado disto, os traços de autoritarismo na comunicação, ancorados em relações hierárquicas, também dificultam atividades participativas, a de planejamento entre elas.

Os profissionais mostraram reconhecer que o desenvolvimento adequado do planejamento pode contribuir para o aprimoramento do processo de trabalho e da eficácia de suas ações. Segundo esses profissionais, o aperfeiçoamento do planejamento no nível das equipes depende diretamente da implementação de estratégias de gestão na saúde, entre as quais destacaram: investimento no espaço físico e no fornecimento de insumos e equipamentos às unidades de saúde, na gestão do trabalho com a inclusão de um profissional com atribuições administrativas em cada unidade, na regulação da rede de serviços e na ampliação de atividades de educação permanente direcionadas ao planejamento.

\section{Considerações finais}

Os resultados encontrados revelaram um planejamento de ações ainda focado em aspectos biológicos, com tendências normativas, sem considerar suficientemente critérios de risco e vulnerabilidade e sem a utilização adequada de instrumentos preconizados para o seu desenvolvimento.

A permanência do modelo biológico é confirmada em outros estudos, como os desenvolvidos recentemente em equipes de Saúde da Família em Ribeirão Preto (SP). De acordo com seus autores, aspectos do modelo biomédico muitas vezes predominam, com atendimentos clínicos e de caráter curativo, centrados na doença e tendo o médico como figura mais importante (SEABRA et al., 2008).

O planejamento de ações nas equipes estudadas se mostrou também como um processo fragmentado, descontínuo e insuficiente, o que limita a competência dos profissionais na gestão da saúde da população em seus territórios de abrangência. A sobrecarga de atividades associada a inadequações na logística da dinâmica de trabalho comprometem as possibilidades das equipes superarem as dificuldades identificadas e aprimorarem o seu processo de planejamento de ações. Capozzolo (2003, p. 275), em estudo realizado no município de São Paulo, relatou resultados semelhantes, em que os profissionais médicos relataram o sentimento de estarem "no olho de um furacão". 
A demanda contínua de usuários e gestores tende a favorecer uma atuação sob permanente pressão, sem suficiente clareza quanto a critérios e metas capazes de orientar o processo de trabalho. $\mathrm{O}$ apoio de grupos técnicos, vinculados à gestão regional e central da Secretaria Municipal de Saúde, se mostrou importante, porém ainda insuficiente para fazer avançar as ações de planejamento nas equipes estudadas. Traços de autoritarismo nas relações entre gestores e profissionais e também entre os profissionais no interior das equipes, apoiados em posições hierárquicas, limitam o diálogo e a participação e inibem a construção compartilhada de um plano local. Neste sentido, a proposta de apoio matricial, através dos Núcleos de Apoio à Saúde da Família - NASF, em que a equipe matricial busca agregar conhecimentos e aumentar a capacidade das equipes locais na resolução dos problemas de saúde, se adequadamente implementada, poderá contribuir para instrumentalizar a autonomia das equipes nas ações de planejamento em seus territórios (BRASIL, 2008).

Fundamental para que gestores, profissionais e usuários dos serviços de saúde possam traçar projetos compartilhados é o reconhecimento de que o trabalho em atenção primária se apóia fortemente em tecnologias leves, que envolvem relacionamentos entre sujeitos, subjetividades e exige competências em comunicação (MERHY, 2007).

Este contexto aponta também para a necessidade de formulação e implementação de metodologias e modelos básicos de instrumentos de planejamento e avaliação, que traduzam as diretrizes da ESF, com capacidade de adequação às peculiaridades e necessidades locais, em cada território. Parece razoável afirmar que sem uma cultura de planejamento participativo que integre e qualifique as ações da ESF, a proposta de transformar o processo de trabalho dos profissionais de saúde, com a consideração dos determinantes e condicionantes sociais da saúde no território, dificilmente será alcançada. Desta forma ficam prejudicadas as propostas de vigilância em saúde, integralidade e equidade das ações e serviços e de controle social.

Investir em formação profissional continuada e permanente, desde o nível técnico, é uma maneira de preparar os profissionais das equipes para o desafio de trabalhar na ESF, incorporando uma nova forma de pensar e agir em saúde. Entretanto, para citar apenas o exemplo da categoria médica, até junho de 2007, somente 605 profissionais das quase 30.000 equipes de Saúde da Família do 
Brasil possuíam o título de especialista em medicina de família e comunidade, o que ilustra o quanto a formação profissional direcionada a ESF ainda necessita de investimentos (FALK, 2007).

Apesar da formação e qualificação profissional e do incremento de tecnologias leves serem fundamentais, não podemos deixar de destacar outros aspectos necessários à operacionalização dos serviços, como a adequação do espaço físico, a disponibilidade de insumos e equipamentos, o número suficiente de profissionais nas equipes e a estruturação e regulação da rede de referência e contrarreferência. Enfim, parece haver ainda um longo trajeto a avançar na mudança do modelo assistencial, tendo a ESF como porta de entrada do sistema, apta a gerenciar a saúde nos territórios com eficiência, eficácia e efetividade.

Concluindo, este estudo nos remeteu a outras questôes relativas às práticas das equipes de Saúde da Família: a família tem sido de fato o foco da atenção das equipes? A que instrumentos as equipes têm acesso para contemplar adequadamente as famílias no planejamento e desenvolvimento de suas açôes. Questôes que poderão orientar um possível desdobramento do presente estudo.

\section{Referências}

ANDRADE, S. M.; SOARES D. A. et al. Bases da Saúde Coletiva. Londrina: UEL, 2001. ARTMANN, E. O planejamento estratégico-situacional: a lógica Matusiana e uma proposta a nível local de saúde. Dissertação (Mestrado em Saúde Pública) - Escola Nacional de Saúde Pública, Fiocruz, Rio de Janeiro, 1993.

ARAUJO, I. N.; CARDOSO, J. M. Comunicação e saúde. Rio de Janeiro: Fiocruz, 2007. 152 p. AZEVEDO, A.L.M.D. et al. Implantação do monitoramento e avaliação da qualidade das informaçōes do SIAB. Revista Brasileira de Medicina de Família e Comunidade, v. 2, p. 9499, 2006.

BARDIN, L. Análise de conteúdo. Lisboa: Edições 70, 2007. 223 p.

BRASIL. Ministério da Saúde. Programa de Saúde da Família: ampliando a cobertura para consolidar a mudança do modelo de atenção básica. Brasília: 2003.

Departamento de Atenção Básica. Evolução do credenciamento e implantação da estratégia Saúde da Família. Disponível em: dab.saude.gov.br. http://dab.saude.gov.br/ historico_cobertura_sf.php Acesso em: 15 abr 2010.

Diretrizes para a programação pactuada e integrada da assistência à saúde. Brasília: MS, 2006. 148 p. 
- Diretrizes operacionais dos pactos pela vida, em defesa do SUS e de gestão. V. 1.Série

Pactos pela Saúde. Brasília: MS, 2006. 76p

. Portaria Ministerial no 154. Cria os Núcleos de Apoio à Saúde da Família - NASF.

Diário Oficial [da] República Federativa do Brasil, Brasília, DF, Ed. 18, p. 47-50, Jan 2008, Seção 1.

- Secretaria de Atenção à Saúde. Departamento de Atenção Básica. Avaliação para a melhoria da qualidade da estratégia saúde da família. Brasília: MS, 2006.

CAMPOS, C.E.A. O desafio da integralidade segundo as perspectivas da vigilância da saúde e da saúde da família. Ciência \& Saúde Coletiva, Rio de Janeiro, v. 8, n. 2, p. 569-584, 2003.

CAPOZZOLO, A.A. No olho do furacão. Trabalho médico e o Programa de Saúde da Família. Tese (Doutorado em Saúde Coletiva) - Departamento de Saúde Coletiva, Universidade Estadual de Campinas. Campinas, 2003.

CARDOSO, A.S.; NASCIMENTO, M.C. Comunicação no Programa Saúde da Família. O agente de saúde como elo integrador entre a equipe e a comunidade. Ciência \& Saúde Coletiva, Rio de Janeiro, v. 15, suppl 1, p. 1509-1520, 2010. Disponível em: http://www.cienciaesaudecoletiva.com.br http://www.scielo.br/scielo.php?script=sci_ arttext \&pid $=$ S1413-81232010000700063\&lng=pt \&nrm $=$ iso

CARDOSO, J. M. Comunicação e saúde: uma ideia e cinco desafios para ampliar a participação e o controle social. In: BRASIL. Ministério da Saúde (Ed.). Seminário de Comunicação, Informação e Informática em Saúde. Comunicação e Saúde: uma ideia e cinco desafios para ampliar a participação e o controle social. Brasília, n. 90, p. 22-32, 2005 (Série D. Reuniōes e Conferências).

COELHO, F.L.; SAVASSI, L. Aplicação de Escala de Risco Familiar como instrumento de priorização das Visitas Domiciliares. Florianópolis: RBMFC, p. 19-26, 2004. Disponível em: http://www.rbmfc.org.br/index.php/rbmfc/article/view/104/pdf

EuláliO, A. M. Planejamento em saúde: Curso de Esp. em Políticas Públicas e Gestão Estratégica em Saúde. Módulo II, aula 4 UFPI. Teresina, 2008. Diponível em: http://www. ufpi.br/nesp/index/pagina/id/3026. Acesso em: 01 Fev 2008.

FALK, J. W. O Título de especialista em Medicina de Família e Comunidade (TEMFC). SBMFC, 2007 Disponível em: http://www.sbmfc.org.br/default.asp?site_ Acao $=$ MostraPagina \& PaginaId = 14http: //www.sbmfc.org.br/default.asp? site Acao $=$ MostraPagina\&PaginaId=14. Acesso em: 10 out 2009.

FOUCAULT, M. Microfísica do poder. São Paulo: Graal. 2007. 295 p.

MERHY, E.E. Em busca do tempo perdido: a micropolítica do trabalho vivo em saúde. In: MERHY, E.E.; ONOCKO, R. (Org.) Agir em saúde: um desafio para o público. São Paulo. Hucitec, 2007, p. 71-112. 
OLIVEIRA, M. M. Como fazer pesquisa qualitativa. Petrópolis: Vozes, 2007

PAIM, J. S. Gestão da atenção básica nas cidades. In: ORGANIZAÇÃO PANAMERICANA DA SAÚDE (Ed.). Saúde nos aglomerados urbanos. Brasília: OPAS, 2003. p. 183-212.

REIS, E.J.B.D. et al. Avaliação da qualidade dos serviços de saúde: notas bibliográficas. Cadernos de Saúde Pública. Rio de Janeiro, v. 6, p. 50-60, 1990.

RIO DE JANEIRO. Subsecretaria de Ações em Serviço de Saúde (SUBASS), 2005. Indicadores da Agenda Municipal. Saúde em Análise. Disponível em: http//www.saude.rio. rj.gov.br/media/indicadores. Acesso em: 5 jun 2008.

RIVERA, F.J.U. A programação local em saúde, os Distritos Sanitários e a necessidade de um enfoque estratégico. Cadernos de Saúde Pública. Rio de Janeiro, v. 5, n. 1, p. 60-81, 1989. SEABRA, D.C. et al. O Agente Comunitário de Saúde na visão da Equipe mínima de saúde. Revista de Atenção Primária de Saúde, v. 11, p. 226-234, 2008.

SÁNCHEZ, A.I.M.; BERTOLOZZI, M.R. Pode o conceito de vulnerabilidade apoiar a constituição do conhecimento em saúde coletiva? Ciência \& Saúde Coletiva. Rio de Janeiro, v. 12, n. 2, p. 319-321. 2007.

TAKEDA, S. A organização de serviços de atenção primária à saúde. In: DUNCAN, B.B.; SCHIMIDT, M.I.; GIUGLIANI, E.R.J. (Org.). Medicina ambulatorial. Porto Alegre:Artmed, 2004. p. 76-87.

TURCI, M. A. Avaliação e acompanhamento da atenção básica no Brasil. Rio de Janeiro: Abrasco, 2008.

\section{Nota}

${ }^{1}$ Criados no município do Rio de Janeiro em 2003, na proporção de um GAT para cada área programática (AP) do município, com o objetivo de oferecer apoio técnico às equipes de Saúde da Família. Cada GAT era composto por diversas categorias profissionais da área da saúde, tais como enfermeiros, psicólogos, dentistas, médicos especialistas etc. No momento da pesquisa, havia nove GAT implantados. Entre suas atribuições, podemos destacar: acompanhar e avaliar o processo de trabalho das equipes, facilitar a articulação de ações de intersetorialidade, elaborar agenda de capacitação e educação permanente. 
The construction of the local plan as an attribution of the Family Healthy Team: the experience of three administrative regions in Rio de Janeiro city

The powers of the Family Health teams include the development of a local plan, with community participation, considering the peculiarities and health needs in each territory. Through a case study with a qualitative approach, we analyzed the local planning process into three teams, located in different program areas of the municipality of Rio de Janeiro. The selection prioritized longer operation and stability in the composition of teams, considering the likelihood of greater internal integration and to their territories. All the professional teams and their regional supervisors participated. Data were collected through direct observation of meetings of teams and semi-structured interviews. We chose to approach content analysis with subject, using the theoretical categories of risk, vulnerability and participatory planning. The results showed a local planning process still in its infancy, no clear definition of common goals, criteria and underuse of recommended instruments, focused on regulatory trends and biological aspects. Among the suggestions for advancing the design, the highlights were the adequacy of physical space in health facilities, stable supply of raw materials, regulation of network services, including an administrative professional in every health unit actions and continuing education. It is understood that the formulation and implementation of methodologies and tools able to translate the basic guidelines of the Family Health Strategy and adapt to the peculiarities of each territory, with the strengthening of a culture of participatory planning is essential to show the integration and skilled labor in these teams.

> Key words: Health Family Strategy, Health Planning, Communication in Health, Family Health Team, Primary Health Care. 